\title{
As tecnologias da informação e da comunicação e a promoção da discussão e ação sociopolítica em aulas de ciências naturais em contexto português
}

\author{
Information and communication technologies \\ and the promoting of the discussion and socio political action \\ in science classrooms in Portuguese' context
}

Neusa Maria John Scheid ${ }^{1}$. Pedro Guilherme Rocha dos Reis ${ }^{2}$

\begin{abstract}
Resumo: Este estudo de revisão da literatura científica publicada recentemente no repositório da Universidade de Lisboa teve como objetivos: (a) investigar o papel das Tecnologias da Informação e da Comunicação (TIC) na promoção da discussão e da ação sociopolítica sobre controvérsias sociocientíficas em contexto escolar, com o intuito de visar, sobretudo, ao desenvolvimento do cidadão nas suas diferentes dimensões, tendo em vista uma participação ativa e fundamentada na sociedade e na resolução de seus problemas; (b) investigar como ocorre o desenvolvimento, a implementação e o estudo de materiais, metodologias e abordagens que apoiem professores e estudantes nesse enfoque da educação em Ciências; e (c) identificar os fatores que influenciam positiva e negativamente o envolvimento nesse tipo de ações. Os resultados das publicações analisadas indicam que as TIC são fundamentais para o desenvolvimento de uma abordagem na perspectiva da educação em Ciências que almeja ser capaz de educar na cidadania.

Palavras-chave: Educação em ciências. Tecnologias da informação e comunicação. Web 2.0. Revisão bibliográfica.
\end{abstract}

\begin{abstract}
This systematic review of scientific literature published recently in the repository of University of Lisbon aimed to: (a) investigate the role of Information Technology and Communication in promoting discussion and sociopolitical action on socio-scientific controversies in schools in order to focus mainly on the development of the citizen in its different dimensions in order to participate actively and grounded in society and solving their problems; (b) investigate how is the development, implementation and study materials, methodologies and approaches that support teachers and students in this approach to science education, and; (c) identify the factors that positively and negatively influence the involvement in such actions. The results of the analyzed publications indicate that ICT is critical for the development of an approach from the perspective of education in Science that aims to be able to educate the people in citizenship.
\end{abstract}

Key words: Science education. ICT. Web 2.0. Bibliographic revision.

\footnotetext{
${ }^{1}$ Universidade Regional Integrada do Alto Uruguai e das Missões (URI), Departamento de Ciências Biológicas, Santo Ângelo, RS, Brasil. E-mail: <scheid.neusa@gmail.com>

${ }^{2}$ Universidade de Lisboa, Instituto de Educação, Lisboa, Portugal.
} 


\section{Introdução}

A evolução da sociedade na utilização intensiva de tecnologias questiona os paradigmas de ensino e aprendizagem tradicionais, fazendo com que o uso das Tecnologias da Informação e Comunicação (TIC) na educação se torne, cada vez mais, imprescindível. Não se pode desconsiderar que os estudantes atuais já nasceram conectados ao computador, internet e dispositivos móveis, como os smartphones e tablets, pois fazem parte da geração de Nativos Digitais (PRENSKY, 2001; VERAS, 2011) para a qual "são necessárias abordagens diferenciadas, que criem um espaço de comunicação entre o professor e o aluno” (CASTANHA; CASTRO, 2010, p. 29).

A utilização das TIC para tornar as aulas mais interessantes e o aprendizado mais significativo tem sido objeto de muitos estudos. Soma-se a isso, o potencial dessas ferramentas na mobilização de diversas competências cruciais para a formação científica e atuação cidadã desses estudantes, considerando-se que as instituições escolares não têm apenas o compromisso de preparar os alunos para receber a herança cultural e compreender os conhecimentos científicos produzidos pela humanidade. Para além dessas dimensões, como refere Zeichner (1993), a escola precisa ter presente sua finalidade democrática e emancipadora, e levar em consideração as dimensões sociais e políticas do ensino. Como afirma Hodson (2003), a educação deverá politizar os estudantes, portanto, não deverá ser sobre a cidadania, mas, para e na cidadania.

Nessa direção, a discussão de questões sociocientíficas e socioambientais controversas ${ }^{3}$, como referidas por Reis e Galvão (2004) e Reis (1997, 2004, 2007, 2013), poderá contribuir para que os estudantes participem em debates e em processos de tomada de decisão, contribuindo para a construção de uma sociedade mais democrática onde todos têm voz. Para Hodson (2011) a ação coletiva, ou ativismo social, surge da necessidade de cada cidadão se fazer ouvir e poder participar nos assuntos relacionados com a ciência, com implicações na sua qualidade de vida e na qualidade de vida em geral. Esse envolvimento dos estudantes em iniciativas de ativismo coletivo sobre questões de interesse ambiental e social, fundamentado em investigação e pesquisa, permite-lhes aumentar o seu conhecimento acerca dos problemas em causa e desenvolver competências de investigação e cidadania participativa e fundamentada - mais do que cidadãos do futuro, os alunos já são cidadãos no presente (REIS, 2013).

Diante desse entendimento, Hodson (2003) alerta que enfrentar os problemas que afetam as sociedades atuais pressupõe compreendê-los, tomar decisões e agir. A ação comunitária baseada em pesquisa e investigação pode considerar-se uma importante dimensão da alfabetização científica.

Se o que se almeja é que esses cidadãos passem da sensibilização para a ação fundamentada, ou seja, que se transformem em produtores ativos de conhecimento, por meio da investigação e da tentativa de mudar situações e comportamentos - da ação sociopolítica (REIS,

\footnotetext{
${ }^{3}$ Segundo Reis (2013, p. 1), as questões sociocientíficas e socioambientais controversas consistem em questões suscitadas por interações entre ciência, tecnologia, sociedade e ambiente que dividem a sociedade, e relativamente às quais diferentes grupos de cidadãos apresentam explicações e possíveis soluções que são incompatíveis, baseadas em crenças, compreensões e valores incompatíveis (LEVINSON, 2006; OULTON; DILLON; GRACE, 2004). Estas questões não conduzem a conclusões simples e envolvem uma dimensão moral e ética (SADLER; ZEIDLER, 2004).
} 
2009, 2013), faz-se necessário que sejam consciente e ativamente envolvidos no processo de aprendizagem. E, para envolvê-los como protagonistas, as TIC surgem como importantes aliadas, pois

\begin{abstract}
Na sociedade da aprendizagem dispomos de novas formas de aprender e de nos relacionarmos com o conhecimento; a aprendizagem ocorre nos mais diversos contextos sejam eles formais ou informais e é um processo que se prolonga ao longo da vida porque o mundo global é competitivo e o que hoje é actual e relevante amanhã estará obsoleto e descontextualizado. Mais do que meros meios de comunicação ou ferramentas neutras, as TIC e a internet são ferramentas tanto cognitivas como sociais que modificam a nossa forma de comunicar, interagir e aprender.” (JONASSEN, 2007 apud COUTINHO; ALVES, 2010, p. 207)
\end{abstract}

No âmbito da realidade portuguesa, está em desenvolvimento o projeto "Promoção de Activismo Comunitário sobre Questões Sociocientíficas - We Act", que pretende construir conhecimento sobre o recurso à ação comunitária fundamentada na resolução democrática de problemas no contexto da Educação em Ciências. O objetivo principal desse projeto é o desenvolvimento, a implementação e o estudo de materiais, metodologias e abordagens que apoiem professores e estudantes na realização de ações informadas e negociadas sobre questões sociocientíficas. Pretende identificar os fatores que influenciam positiva e negativamente o envolvimento nesse tipo de ações, e construir conhecimento sobre os processos de intervenção mais adequados à instrumentação dos professores (dos diferentes níveis de ensino) com a confiança, a motivação e os conhecimentos necessários à estimulação dessas ações informadas junto a seus estudantes (REIS, 2013, 2014).

O projeto We Act combina três aspectos distintos: (i) a discussão de questões sociocientíficas por meio da promoção de uma aprendizagem ativa assente na investigação de situações reais; (ii) a estimulação da participação dos alunos nas ações coletivas de resolução democrática de problemas; (iii) a estimulação dos dois aspectos anteriores por meio de iniciativas envolvendo arte e o recurso a ferramentas da Web 2.0. Embora exista uma quantidade considerável de literatura na área da discussão de questões sociocientíficas, o mesmo não acontece sobre a combinação sinérgica desta área com o recurso a abordagens baseadas em arte e a ferramentas da Web 2.0 na promoção do ativismo e da intervenção social sobre questões sociocientíficas controversas. Esta combinação sinérgica constitui o aspecto inovador desse projeto de investigação-ação, cuja equipe integra participantes de diferentes instituições - escolas básicas e secundárias, institutos politécnicos, universidades, centros de pesquisa em educação e em ciências (REIS, 2014).

A discussão e a ação comunitárias fundamentadas sobre controvérsias sociocientíficas e socioambientais constituem um elemento importante de diversos currículos de ciências internacionais devido as suas potencialidades tanto na aprendizagem dos conteúdos, dos processos e da natureza da ciência e da tecnologia, como no desenvolvimento cognitivo, social, político, moral e ético dos estudantes. Para Marques (2013), o envolvimento dos estudantes em projetos de ativismo implica desenvolver neles capacidades de ativismo (competências de conhecimento, de raciocínio, de comunicação e de atitudes) que os levem a querer agir e, de fato, agir. 
Diante desse contexto, elaboramos o presente estudo, que se caracteriza como uma revisão da literatura científica publicada nos últimos quatro anos (2011-2014), no Repositório da Universidade de Lisboa (2015), sobre investigações desenvolvidas no âmbito do Instituto de Educação dessa universidade, e que foi realizado com os objetivos de: (a) investigar o papel das Tecnologias da Informação e da Comunicação (TIC), nomeadamente, dos recursos da Web 2.0 na promoção da discussão e da ação sociopolítica sobre controvérsias sociocientíficas em contexto escolar, com o intuito de visar, sobretudo, ao desenvolvimento do cidadão nas suas diferentes dimensões (conhecimento, capacidades e atitudes), tendo em vista uma participação ativa e fundamentada na sociedade e na resolução de seus problemas; (b) investigar como ocorre o desenvolvimento, a implementação e o estudo de materiais, metodologias e abordagens que apoiem professores e estudantes nesse enfoque da Educação em Ciências; (c) identificar os fatores que influenciam positiva e negativamente o envolvimento nesse tipo de ações e (d) construir conhecimento sobre os processos de intervenção mais adequados à instrumentação dos professores (dos diferentes níveis de ensino) com a confiança, a motivação e os conhecimentos necessários à estimulação dessas ações informadas.

\section{Percurso metodológico}

A investigação realizada caracteriza-se como qualitativa, que, consoante Gonçalves (2010), deve ser entendida como um processo simultaneamente interrogativo e reflexivo fundamentado em uma perspectiva compreensiva, surgindo da necessidade de compreender e interpretar o significado dos fenômenos sociais. Assim, a presente investigação teve como objetivo último a seguinte questão problematizadora: "quais as potencialidades e quais as dificuldades do uso das TIC no ensino de Ciências Naturais para a promoção da discussão e da ação sociopolítica sobre controvérsias sociocientíficas em contexto escolar, com o intuito de visar, sobretudo, ao desenvolvimento do cidadão nas suas diferentes dimensões (conhecimento, capacidades e atitudes), tendo em vista uma participação ativa e fundamentada na sociedade e na resolução de seus problemas?”. Atentos à advertência de Bogdan e Biklen (1994), para que a investigação ficasse protegida da especulação não fundamentada, os dados foram recolhidos de forma sistemática e rigorosa. Segundo Gray (2012), as técnicas para essa recolha incluem: o uso de observações, entrevista, questionários e análise de documentos, sendo essa última técnica considerada a mais adequada para ser utilizada na presente investigação.

A coleta dos dados ocorreu no primeiro semestre de 2014. Foram analisadas as publicações de 02 de janeiro de 2010 a 31 de maio de 2014 que constavam no repositório da Universidade de Lisboa (2015), produzidas no âmbito do Instituto de Educação dessa universidade e que continham em seus resumos como palavras-chaves: TIC, Web 2.0, e-portfólios, multimídia, controvérsias sociocientíficas, questões controversas, ativismo. A decisão por esse repositório, para a coleta de dados que constituíram o corpus de pesquisa, ocorreu pela acessibilidade proporcionada pela realização de um estágio pós-doutoral pela primeira autora no Instituto de Educação da Universidade de Lisboa, nesse período. Segundo Gil (2007), na amostragem não probabilística por acessibilidade, o pesquisador seleciona os elementos a que tem acesso, admitindo que estes possam representar o universo. 
Para o estudo dos dados, foi utilizada a técnica de análise de conteúdo, que Bardin (2004, p. 37) define como "um conjunto de técnicas de análise das comunicações, que utiliza procedimentos sistemáticos e objetivos de descrição do conteúdo das mensagens”, aplicandose, portanto, à análise de textos escritos ou à comunicação oral. O procedimento inicial foi a decodificação dos dados contidos nas publicações selecionadas. Para orientar o estudo, foram elaboradas categorias de análise, validadas pelo pesquisador supervisor do estágio pós-doutoral da primeira autora, conforme as funções atribuídas às TIC na Educação em Ciências: (i) TIC como ferramentas educacionais para construir conhecimento substantivo sobre conteúdos específicos da área; (ii) TIC como facilitadoras do desenvolvimento de capacidades de raciocínio, de comunicação e de argumentação fundamentadas; (iii) TIC como promotoras de ativismo.

Os resultados da análise de doze publicações consideradas mais relevantes para o estudo, de acordo com essas três categorias elaboradas, são apresentados a seguir.

\section{As TIC como ferramentas educacionais para construir conhecimento substantivo sobre conteúdos específicos da área}

Muitos professores têm a preocupação de utilizar TIC em suas aulas como forma de melhorar a motivação e o interesse dos estudantes, buscando aprendizagens significativas (PEREIRA, 2010), pois entendem essas ferramentas como aliadas para facilitar o trabalho pedagógico. Conforme Moran (2000, p. 23), “[...] um dos grandes desafios para o educador é ajudar a tornar a informação significativa, a escolher as informações verdadeiramente importantes entre tantas possibilidades, a compreendê-las de forma cada vez mais abrangente e profunda e a torná-las parte do nosso referencial".

As TIC podem contribuir significativamente nesse aspecto, cabendo, ao professor, conhecer e avaliar o potencial das diversas mídias ao seu alcance, e oportunizar o uso consciente por seus alunos, com o objetivo de envolvê-los e apoiá-los na construção de conhecimentos científicos.

Nesse contexto, a investigação desenvolvida por Faria (2011) procurou analisar a utilização colaborativa de um Wiki ${ }^{4}$, enquanto artefato tecnológico para a aprendizagem formal e informal de conteúdos sobre Darwin. O estudo envolveu dois docentes de três turmas do $11^{\circ}$ ano do Ensino Secundário e 69 alunos, de uma escola privada de Lisboa. A temática foi primeiramente abordada nos contextos previstos no programa, para ser, posteriormente, explorada e aprofundada, em trabalho de grupo.

Conforme o autor, os resultados encontrados mostraram o Wiki como ferramenta com potencial para a aprendizagem colaborativa e, por meio dessa, para a construção de conhecimentos específicos, como foi o caso do estudo sobre Darwin. No entanto, o autor alerta que:

Esta experiência mostrou que apesar dos alunos envolvidos terem amplo contato com as TIC, muito existe para descobrir e explorar, quer a nível

\footnotetext{
${ }^{4}$ Um Wiki é um Website para o trabalho coletivo de um grupo de autores. A sua estrutura lógica é muito semelhante à de um Blogue, mas com a funcionalidade acrescida de qualquer visitante poder clicar para modificar, agregar ou suprimir o conteúdo da página, ainda que este tenha sido criado por outros autores (COUTINHO; BOT'TENTUIT JUNIOR, 2007).
} 
da integração na aprendizagem, quer a nível da exploração em função de interesses próprios. A integração em contextos de aprendizagem de ferramentas TIC continua, ainda, a ser uma novidade para muitos alunos, mesmo com 10 anos de frequência escolar. Contudo, a sua integração carece de uma apropriada exploração por parte do professor, já que disso depende um sucesso e, como tal uma motivação para replicar a experiência ou introduzir novas, ou um fracasso e, nessas circunstâncias a usual desistência e abandono destas ferramentas. (FARIA, 2011, p. 63)

Resultados semelhantes foram encontrados por Albano (2012) ao investigar qual a percepção que alunos e professores teriam da utilização de recursos Web 2.0 na aprendizagem de multimídia, e qual o tipo de recursos mais adequado para o ensino desse currículo. Participaram da investigação três professores e 33 alunos de uma escola secundária de Lisboa que frequentavam o Curso Profissional Técnico de Multimídia ou o Curso de Educação e Formação de Adultos de Dupla Certificação em Informática, ambos os cursos desenvolvidos numa perspectiva de e-learning e de utilização intensiva de materiais Web 2.0. Segundo o autor, por meio dos mais variados processos de coleta de dados junto ao grupo participante, incluindo alunos e professores, pode-se perceber que o uso de plataformas de aprendizagem (LMS) e da Web 2.0 teve um efeito positivo como catalisador da aprendizagem.

Albano (2012, p. 114) alerta que qualquer modalidade de aprendizagem, seja e-learning, b-learning ou presencial, deve estar fundamentada em estruturas pedagógicas claras, "onde os objetivos educacionais presidem à utilização das ferramentas e não o seu contrário”, pois são "antes um meio que deverá permitir processos eficazes de aprendizagem, nomeadamente, no desenvolvimento de comunidades de alunos que possam querer seguir um percurso autónomo".

No estudo "O ensino de Biologia e Geologia com recursos às Tecnologias da Informação e Comunicação: implicações para a aprendizagem”, Monteiro (2013), investigou como uma integração das TIC bem planejada e implementada no ensino das Ciências numa perspectiva de "Ensino Por Pesquisa" poderia influenciar o processo de aprendizagem, e, simultaneamente, desenvolver outras competências, como a autonomia e a autorregulação, contribuindo para o sucesso escolar geral do aluno e sua formação como cidadão. Nessa investigação foram envolvidos 102 alunos durante dois anos letivos. Os resultados obtidos indicam que a utilização de e-portfólios inserida num "Ensino por Pesquisa" com recurso ao computador e à Internet é uma excelente estratégia motivadora e desafiante de ensino e aprendizagem. A autora, a exemplo de Albano (2012), chama a atenção para a necessidade da compreensão do papel das TIC na educação, pois é preciso considerá-las como ferramentas pedagógicas. Nesse sentido, a aplicação de uma ferramenta passa pelo estabelecimento de critérios de escolha de metodologias e estratégias apropriadas a cada situação pedagógica, numa perspectiva de inovação pedagógica, e não de invenção técnica. Concordamos com os autores quando afirmam que, para reconhecer a importância e levar a tecnologia para a sala de aula, é crucial que o professor mude as suas concepções de ensino e de Ciências.

Valério (2012) buscou compreender a possibilidade, por meio de experiências de aprendizagem que envolvessem os estudantes na construção e divulgação de podcasts e vodcasts, de desenvolver competências e atingir metas de aprendizagem no âmbito do ensino da Química, e como essa integração de ferramentas, nas práticas didáticas, pode ser uma mais valia 
para a motivação dos alunos. Os resultados obtidos demonstraram que o uso de TIC no ensino aumentou significativamente a motivação dos 16 alunos do $9^{\circ}$ ano envolvidos na investigação, pois lhes permitiu um papel mais ativo no uso de competências, possibilitando a produção de conhecimento próprio e passível de ser partilhado com os outros.

Por outro lado, consoante ao desafio, colocado aos professores da Educação Básica em Ciências Naturais, de cumprir com os programas, de não esquecer as exigências das avaliações externas como as provas de vestibular e do Exame Nacional de Ensino Médio (ENEM) ao final dessa escolaridade, solicita-se aos mesmos que sejam capazes de desenvolver, nos estudantes, competências de manipulação e transformação da informação em conhecimento, sob a forma de aprendizagens significativas (AUSUBEL, 2003). Isso implica que os objetivos para os alunos não devem limitar-se à aprendizagem dos conteúdos científicos, mas sejam capazes de desenvolver competências que lhes permitam participar e interagir num mundo global, altamente competitivo, que valoriza o ser flexível, comunicativo, criativo e aprendente ao longo de toda a vida (GALVÃO, 2001; POZO, 2004).

Com essa compreensão das finalidades da Educação em Ciências, como as TIC poderão facilitar a tarefa do professor? Vejamos algumas respostas na segunda categoria de análise elaborada nesse estudo.

\section{As TIC como facilitadoras do desenvolvimento de capacidades de raciocínio, de comunicação e de argumentação fundamentadas}

As Tecnologias da Informação e Comunicação (TIC) apresentam-se com diferentes modalidades. As ferramentas Web 2.0 estão tornando a Web uma plataforma de produção poderosa, e a sua inclusão nos dispositivos móveis está em expansão. Delgado (2014), em sua tese de doutoramento, investigou as aprendizagens em Ciências Naturais que são possíveis promover com recurso às tecnologias ubíquas ${ }^{5}$ (TU) num quadro de metodologias centradas no aluno. Nesse estudo, estiveram envolvidos em torno de oitenta estudantes portugueses ao longo de três anos letivos consecutivos. A autora destaca que,

O conjunto das atividades e dos desafios com TU contribuiu para que os alunos desenvolvessem: (i) competências associadas à literacia científica, nomeadamente competências do domínio do raciocínio (identificação de problemas, formulação de hipóteses, definição de planos de ação, planeamento de procedimento experimental, resolução de problemas, organização de ideias, interpretação de dados/resultados e realização de inferências); do domínio do conhecimento (aquisição de conhecimentos; compreensão de temas/assuntos; aplicação de conceitos a novas situações), do domínio da comunicação (argumentação e explicitação de ideias, apresentação oral e escrita de trabalhos; forma de escrita) e do domínio das atitudes (autonomia, criatividade, respeito, responsabilidade, interesse, motivação e participação);

\footnotetext{
${ }^{5}$ Por tecnologias ubíquas (TU) entendem-se os dispositivos tecnológicos omnipresentes que permitem obter informações a qualquer momento e em qualquer lugar, e de que são exemplos: os telemóveis, leitores de Mp3 e Mp4, leitores de livros digitais, computadores portáteis, PDA, smartphones e tablets (DELGADO, 2014).
} 
(ii) competências ligadas à literacia digital, através do uso do telemóvel e do computador portátil, respetivos softwares e aplicações online, na elaboração de uma diversidade de produtos e de realizações. (DELGADO, 2014, p. 254)

Os resultados dessa investigação ratificam o elevado potencial que tem sido associado às TU e que já havia sido reconhecido pela UNESCO, em 2012, quando enunciou as recomendações de evitar a proibição de dispositivos móveis nas salas de aula e incorporar as tecnologias móveis nos programas de formação de professores (VOSLOO, 2012).

Outra modalidade de TIC, mais conhecida e utilizada em salas de aulas, são os blogues. Sobre o seu potencial para a Educação em Ciências no desenvolvimento de capacidades de raciocínio, de comunicação e de argumentação fundamentadas, encontramos o estudo de Espírito Santo (2012). A investigação teve como finalidade estudar as potencialidades educativas da discussão de assuntos controversos utilizando blogues, e foi efetuada com 24 alunos de uma turma do quinto ano de escolaridade de uma escola da região de Lisboa e Vale do Tejo, na disciplina de Ciências da Natureza.

Como afirma a autora, os resultados obtidos permitiram verificar que a discussão em torno do cenário proposto permitiu a aquisição e o desenvolvimento de competências indispensáveis na promoção da alfabetização científica, que a atividade foi avaliada de forma positiva pelos alunos, pois o fato de ser contextualizada numa situação real do quotidiano levou-os a reconhecerem o interesse da Ciência para o dia a dia. Também pode se constatar que a utilização de blogues poderá constituir uma mais-valia, de modo que os alunos, mais facilmente, possam construir conhecimento e desenvolver competências básicas.

A discussão de vídeos também poderá ser uma importante forma de utilização das TIC como potencial educativo. Linhares e Reis (2012) publicaram os resultados de uma investigação que buscou estudar as potencialidades educativas da discussão de controvérsias sociocientíficas baseada em documentários em vídeo. Foram colaboradores, nessa pesquisa, alunos de duas turmas dos cursos de Licenciatura em Educação Básica (futuros educadores de infância e professores do $1 .^{\circ}$ e $2 .^{\circ}$ ciclos do Ensino Básico), que frequentavam a unidade curricular de Ambiente e Desenvolvimento Sustentável (ADS), em Portugal. A discussão ocorreu utilizando-se o recurso de dois documentários em vídeo sobre o tema do superaquecimento global, tendo, ambos os vídeos, perspectivas distintas para explicar o fenômeno. De acordo com os autores, "o confronto funcionou, nos alunos, como um estímulo no processo de análise dos argumentos apresentados. Esta análise contribuiu para a promoção do raciocínio dos alunos que, pela organização de ideias, possibilitou uma melhor compreensão do problema” (LINHARES; REIS, 2012, p. 118).

Afirmam, ainda, que:

Os documentários em vídeo sobre temáticas atuais, relevantes e controversas parecem ser aqueles que reúnem maiores potencialidades na promoção de discussões em contexto educativo. Os dados revelam que um tema com estas características reúne atributos mais favoráveis, suscitando maior interesse e motivação nos alunos e, consequentemente, uma discussão mais participada e significativa. Apenas através de atividades de discussão poderemos evoluir de um conhecimento do senso comum para um verdadeiro conhecimento 
científico. Assim, torna-se essencial recorrer com maior frequência a este tipo de metodologia educativa nos diferentes níveis de ensino. (LINHARES; REIS, 2012, p. 118)

Em outro estudo mais amplo, Linhares (2013), desenvolveu uma investigação objetivando investigar as potencialidades e as limitações da discussão de questões controversas, como metodologia de educação em ciências no Ensino Superior. Os dados obtidos permitiram obter evidências quanto: à diversidade de competências desenvolvidas nos alunos, à mudança de concepções alternativas e ao aprofundamento de conhecimentos por meio da discussão. De acordo com a autora, alguns fatores facilitadores da discussão relacionam-se com a organização das atividades, os temas selecionados e a atribuição de tarefas individuais dentro do grupo. Por outro lado, as dificuldades detectadas remetem para a concepção, gestão e avaliação da discussão pela professora; e, em relação aos alunos, destacam-se os problemas de gestão de tempo e as dificuldades de tomada de decisão.

Esses resultados da investigação realizada por Linhares (2013) sugerem que este tipo de experiência educativa pode desencadear uma evolução nas competências cognitivas, comunicacionais, sociais e democráticas, contribuindo para a alfabetização científica dos indivíduos e para a integração destas atividades nas futuras práticas didáticas destes futuros professores.

Com o objetivo de promover as capacidades de pensamento crítico e de argumentação fundamentada em investigação, Fanica (2012) envolveu dezessete alunos da disciplina de Física do $12 .^{\circ}$ ano na discussão de controvérsias sociocientíficas por meio da utilização da plataforma Moodle. Os resultados evidenciaram uma variação da qualidade argumentação de acordo com vários fatores, nomeadamente, o tema em discussão e a introdução na atividade de questões orientadoras da argumentação. Constatou, igualmente, que os fóruns de discussão facilitam o desenvolvimento de capacidades de comunicação, argumentação e reflexão e, ainda, proporcionam a promoção de uma concepção de ciência como empreendimento dinâmico marcado pela controvérsia (REIS, 1997, 2004).

Como se pode perceber, os resultados dessas investigações permitem a ilação de que a utilização de TIC em aulas de Ciências Naturais auxilia no desenvolvimento de capacidades de raciocínio, de comunicação e de argumentação fundamentadas. No entanto, como afirma Reis (2013, 2014), o que se almeja na Educação em Ciências como finalidade mais superior é que os estudantes passem da sensibilização para a ação fundamentada, ou seja, que se transformem em produtores ativos de conhecimento, por meio da investigação e da tentativa de mudar situações e comportamentos - a ação sociopolítica. Isso é o que se denomina de ativismo e que será o tema de análise na próxima categoria.

\section{As TIC como promotoras de ativismo}

No âmbito do projeto We Act, estão sendo desenvolvidos diversos trabalhos na promoção de ativismo (REIS, 2014). De acordo com Hilário e Reis (2009), o ativismo é promovido a partir de experiências educativas, na qual se debatem temas controversos de questões sociocientíficas que constituem uma experiência escolar enriquecedora e potencializadora do desenvolvimento de múltiplas competências. Nesse estudo, destacaremos os trabalhos de d'Abreu (2013), Esperto (2013) e Marques (2013), que foram realizados com esse propósito explícito. 
Identificar as potencialidades da dinamização de um blogue, na estimulação do ativismo e da intervenção social em 19 alunos do quinto ano de escolaridade básica de uma escola de Lisboa sobre problemas ambientais foi o objetivo da investigação desenvolvida por d'Abreu (2013). A metodologia de investigação foi essencialmente qualitativa, considerando que a pesquisadora investigou a sua própria prática por meio da aplicação de uma proposta didática e da dinamização de um blogue. Como métodos de recolha de dados, foram utilizados: um questionário, entrevistas semiestruturadas e documentos escritos, que incluíram o conteúdo do blogue e as respostas às questões de uma atividade realizada em casa, porém, discutida em contexto de sala de aula.

A autora destaca que, de modo geral, não se verificou, nos alunos, um impacto positivo no que diz respeito aos conhecimentos, capacidades ou atitudes, pois os alunos não se comprometeram verdadeiramente com o ativismo. No entanto, em relação à iniciativa implementada, observou progressos em relação às competências de comunicação e pensamento crítico quando da discussão da atividade em sala de aula. Para d'Abreu (2013), as atividades propostas permitiram ir ao encontro de dois dos quatro níveis de sofisticação dos currículos CTSA (Ciência, Tecnologia, Sociedade e Ambiente) propostos por Hodson (2003): (i) ajudar os alunos a formularem as suas opiniões acerca das questões importantes e a estabelecerem posições em torno de determinados valores e (ii) preparar para agirem responsavelmente no que diz respeito ao ambiente e à sociedade.

Assim, em relação aos resultados observados, pode-se inferir que o tempo de seis meses para a aplicação da proposta didática, aliado à faixa etária dos alunos, com idades entre nove e doze anos, acostumados a um ensino não centrado no aluno, podem ter sido as razões principais de não terem sido alcançados os objetivos na sua plenitude. No entanto, "as dificuldades experimentadas constituíram um bom catalisador de reflexão e de construção de conhecimento didático tendo em vista a sua superação", como afirma d'Abreu (2013, p. 75).

Em outro estudo, Esperto (2013) realizou uma investigação com 28 alunos de uma turma do sétimo ano da Educação Básica de uma escola portuguesa, durante o ano letivo de 2012/2013. Nas aulas de Educação para a Cidadania Responsável, que ocorriam em um período de 45 minutos semanais, os estudantes realizaram atividades de resolução de problemas contextualizadas em situações do quotidiano, relacionadas com problemas sociais enquadrados no âmbito da temática Educação Rodoviária. Para apresentação da temática, foram utilizados, pelos estudantes, diversos recursos das TIC, tais como: a criação de filmes, bandas desenhadas utilizando a Web 2.0, pequenas peças de teatro, Power Point, produção de panfletos e cartazes.

Os resultados obtidos corroboram a perspectiva de Strauss e Westland (2005 apud ESPERTO, 2013), segundo a qual a abordagem (discussão/resolução de problemas de controvérsias sociocientíficas) potencia o desenvolvimento de competências como: escutar, debater, resolver conflitos, pensar de forma crítica e ser criativo na resolução de problemas. Conforme a autora,

A partir dessas atividades no âmbito do ativismo, na sala de aula, é possível introduzir práticas que desenvolvem a pesquisa, a discussão, a crítica, a reflexão, a comunicação, a partilha, o trabalho colaborativo e o raciocínio, havendo progressivamente a aquisição de competências fundamentais que permitirão que os jovens entendam os contextos e as problemáticas sociais 
e consequentemente, contribuirão para o exercício de uma cidadania ativa e responsável. (ESPERTO, 2013, p. 105)

Ao discutir a temática da Educação Rodoviária, além de desenvolver as competências conforme previsto na disciplina de Educação para a Cidadania Responsável e aprender conteúdos no âmbito da disciplina de Físico-Química, previstas no Currículo Nacional de Ensino Básico português, foram promovidas competências que contribuíram para a construção de uma sociedade mais justa e democrática, o que está em acordo com a finalidade do projeto We Act.

Para verificar empiricamente as potencialidades de uma abordagem interdisciplinar entre as Ciências Naturais e a Tecnologias da Informação e da Comunicação no desenvolvimento de um projeto de ativismo ambiental, Marques (2013) realizou uma investigação envolvendo trinta alunos de oitavo ano e dois professores de uma escola do Concelho de Cascais. Durante um semestre letivo, os alunos, com idades entre 12 e 16 anos, envolveram-se num projeto de ativismo ambiental sobre uma temática atual e pertinente - a poluição. O desenvolvimento desse projeto interdisciplinar oportunizou aos alunos investigarem diferentes aspectos relacionados com o tema poluição, com a finalidade de adquirirem conhecimento que lhes permitisse a construção de vídeos visando à sensibilização e a mudança de comportamentos da comunidade escolar.

A culminância do projeto ocorreu com a produção de 14 vídeos de autoria dos alunos participantes, que foram divulgados em sessões de apresentação intraturma e interturmas, além de serem disponibilizados no Web site da escola. Marques (2013, p. 7) concluiu que "[...] os resultados obtidos indicam que a maioria dos alunos, através das estratégias adotadas e das situações de aprendizagem criadas, conseguiu, de um modo bastante satisfatório, desenvolver competências nos domínios Conhecimento, Raciocínio, Comunicação, Atitudes e Ativismo”.

A autora destaca que, durante o desenvolvimento, as principais dificuldades reveladas foram em relação: ao processo de pesquisa, análise, seleção e síntese de informação. Para os alunos, de modo geral, conforme seus comentários, o projeto foi muito positivo, destacando seu particular entusiasmo nas etapas de construção e divulgação dos vídeos.

Por se tratar de um projeto interdisciplinar, houve a possibilidade do "desenvolvimento de competências tecnológicas numa situação contextualizada” (MARQUES, 2013, p. 7). Logo, o aluno não aprendeu a lidar com a tecnologia pelo domínio técnico apenas, mas a utilizou na resolução de um problema significativo - o de sensibilizar a comunidade para a questão da poluição.

Nesse contexto, as TIC revelaram-se ferramentas essenciais para a promoção do ativismo que, resumidamente, pretende oferecer condições para que o aluno/cidadão seja capaz de:

${ }^{*}$ Reconhecer a importância e o dever de participar e desenvolver iniciativas que contribuam para a resolução de problemas sociais;

${ }^{*}$ Reconhecer possuir as capacidades para desenvolver iniciativas que contribuam para a resolução de problemas sociais;

${ }^{*}$ Conhecer meios/formas através dos quais pode desenvolver iniciativas que contribuam para a resolução de problemas sociais. (MARQUES, 2013, p. 161)

Esse grupo de alunos, ao produzir e divulgar vídeos para sensibilizar a comunidade escolar, além de aprender conceitos científicos sobre o tópico curricular - Poluição - inserido 
na unidade temática Perturbações no Equilíbrio dos Ecossistemas, aprendeu a lidar com recursos da Web 2.0. Porém, o mais valioso para sua formação pessoal e cidadã foi vivenciar essa oportunidade de desenvolvimento de competências de ativismo.

\section{Considerações finais}

A análise das publicações desse estudo evidencia que existem muitas potencialidades nas TIC para a promoção da discussão e da ação sociopolítica sobre questões sociocientíficas e socioambientais controversas em contexto escolar, com o intuito de visar, sobretudo, ao desenvolvimento do cidadão nas suas diferentes dimensões (conhecimento, capacidades e atitudes), tendo em vista uma participação ativa e fundamentada na sociedade e na resolução de seus problemas.

Em especial, os recursos da Web 2.0, são importantes para o desenvolvimento de uma abordagem na perspectiva da Educação em Ciências que almeja ser capaz de educar para a cidadania e na cidadania. Para que isso se efetive, é importante pontuar que, ao contrário do que se poderia pensar, as tecnologias não vieram substituir o professor, mas, antes, promover uma mudança, de paradigma educacional, a que se associa, naturalmente, uma alteração das práticas educativas, substituindo a escola centrada no ensino, por uma escola centrada nas aprendizagens (LIMA; CAPITÃO, 2003; PAPERT, 2001).

Embora as pesquisas indiquem a significativa contribuição das TIC nos aspectos abordados neste artigo, há uma restrita utilização das mesmas em aulas de Ciências Naturais. Isso pode ter como causa o fato de, muito raramente, nos cursos de formação profissional inicial, ou continuada, os professores serem instrumentalizados para a utilização das TIC com finalidade educativa. Além disso, falta-lhes capacitação e condições/tempo para o planejamento e implementação de projetos interdisciplinares.

Em síntese, esse estudo, embora tenha presente as limitações apresentadas, uma vez que ficou restrito a algumas pesquisas em contexto português, permite algumas ilações para os mais diversos contextos educativos atuais, como: (i) é urgente e imperativa a necessidade de se eliminarem contextos de ensino ultrapassados e irrelevantes e de se permitir, aos professores, desenvolverem novos conhecimentos e capacidades pedagógicas; (ii) para uma educação em Ciências adequada é preciso incentivar os professores e criar espaços/tempos para que possam partilhar experiências e práticas de abordagens investigativas para ensino, aprendizagem e avaliação utilizando as TIC em sala de aula; (iii) esse uso das TIC, especialmente os recursos da Web 2.0, deverá envolver os alunos em projetos de ativismo, que os levem a não apenas querer agir, mas, de fato, agir como cidadãos no presente, e não apenas no futuro.

\section{Agradecimentos}

Agradecemos à Coordenadoria de Aperfeiçoamento de Pessoal de Nível Superior (CAPES) pela bolsa concedida para a realização do Estágio Pós-Doutoral no Instituto de Educação da Universidade de Lisboa, no período de fevereiro a julho de 2014, sob a supervisão do Professor Doutor Pedro Guilherme Rocha dos Reis. 
As tecnologias da informação e da comunicação ...

\section{Referências}

ALBANO, N. J. A. Utilização de tecnologia web 2.0 na aprendizagem autónoma de multimédia. 126 f. Dissertação (Mestrado em Educação) - Instituto de Educação, Universidade de Lisboa, Lisboa, 2012. Disponível em: < http://repositorio.ul.pt/ handle/10451/7547>. Acesso em: 12 nov. 2015.

AUSUBEL, D. Aquisição e retenção de conhecimentos: uma perspetiva cognitiva. Lisboa: Plátano, 2003.

BARDIN, L. Análise de conteúdo. 3. ed. Lisboa: Edições 70, 2004.

BOGDAN, R.; BIKLEN, S. Investigação qualitativa em educação: uma introdução à teoria e aos métodos. Porto: Porto Editora, 1994.

CASTANHA, D.; CASTRO, M. B. A necessidade de refletir sobre as estratégias pedagógicas para atender à aprendizagem da geração Y. Revista de Educação do COGEIME, São Paulo, v. 19, n. 36, p. 27-38, 2010. Disponível em: <http://www.cogeime.org.br/wpcontent/uploads/2011/11/36Artigo02.pdf >. Acesso em: 18 set. 2013.

COUTINHO, C. P.; ALVES, M. C. F. Educação e sociedade da aprendizagem: um olhar sobre o potencial educativo da internet. Revista de Formación e Innovación Educativa Universitaria, Vigo, v. 3, n. 4, p. 206-225, 2010. Disponível em: <http://repositorium.sdum. uminho.pt/handle/1822/11229>. Acesso em: 12 nov. 2015.

COUTINHO, C.; BOTTENTUIT JUNIOR, J. B. Collaborative learning using wiki: a pilot study with master students in educational technology. In: MONTGOMERIE, C.; SEALE, J. (Ed.). Proceedings of EdMedia: World Conference on Educational Media and Technology. [Waynesville]: AACE, 2007. p. 1786-1791. Disponível em: < https://repositorium.sdum. uminho.pt/bitstream/1822/6720/1/Edmedia2007.pdf >. Acesso em: 12 nov. 2015.

D'ABREU, R. T. V. Os blogues e o ativismo sobre problemas ambientais no 5 . $^{\circ}$ ano de escolaridade. 103 f. Dissertação (Mestrado em Educação) - Instituto de Educação, Universidade de Lisboa, Lisboa, 2013. Disponível em: < http://repositorio.ul.pt/ handle/10451/9903>. Acesso em: 12 nov. 2015.

DELGADO, V. H. L. Tecnologias ubíquas nas aulas de ciências naturais: da surpresa à valorização e utilização plena - um estudo longitudinal. 1507 f. Tese (Doutoramento em Educação) - Instituto de Educação, Universidade de Lisboa, Lisboa, 2014. Disponível em: <http://repositorio.ul.pt/handle/10451/10662>. Acesso em: 12 nov. 2015.

ESPERTO, A. P. A. A promoção da literacia científica e da cidadania através de ativismo fundamentado. $148 \mathrm{f}$. Dissertação (Mestrado em Educação) - Instituto de Educação, Universidade de Lisboa, Lisboa, 2013. Disponível em: <http:/ repositorio.ul.pt/ bitstream/10451/9954/1/ulfpie044817_tm.pdf >. Acesso em: 12 nov. 2015.

ESPÍRITO SANTO, M. M. Utilização de blogues na discussão de controvérsias sociocientíficas na disciplina de ciências da natureza. 71 f. Dissertação (Mestrado em Educação) - Instituto de Educação, Universidade de Lisboa, Lisboa, 2012. Disponível em: <http:/ /repositorio.ul.pt/handle/10451/8104>. Acesso em: 12 nov. 2015. 
FANICA, J. F. C. A promoção da argumentação nas aulas de física do $12 .^{\circ}$ ano com recurso à discussão de controvérsias sociocientíficas. $141 \mathrm{f}$. Dissertação (Mestrado em Didática das Ciências) - Instituto de Educação, Universidade de Lisboa, Lisboa, 2012. Disponível em: < http://repositorio.ul.pt/handle/10451/8174>. Acesso em: 12 nov. 2015.

FARIA, A. N. M. M. C. Utilização do wiki como ferramenta colaborativa de aprendizagem. 143 f. Dissertação (Mestrado em Educação) - Instituto de Educação, Universidade de Lisboa, Lisboa, 2011. Disponível em: < http://repositorio.ul.pt/ handle/10451/6252>. Acesso em: 12 nov. 2015.

GALVÃO, C. (Coord.). Ciências físicas e naturais: orientações curriculares $3^{\circ}$ ciclo. Lisboa: Ministério da Educação, 2001. Disponível em: <http://www.dge.mec.pt/sites/ default/files/ficheiros/eb_cfn_orient_curriculares_3c_1.pdf>. Acesso em: 12 nov. 2015.

GIL, A. C. Como elaborar projetos de pesquisa. 4. ed. São Paulo: Atlas, 2007.

GONÇALVES, T. N. R. Investigar em educação: fundamentos e dimensões da investigação qualitativa. In: ALVES, M. G.; AZEVEDO, N. R. (Ed.). Investigar em educação: desafios da construção de conhecimento e da formação de investigadores num campo multi-

referenciado. Lisboa: Universidade Nova de Lisboa, 2010. p. 39-63. Disponível em: <http:/ / run.unl.pt/bitstream/10362/5287/1/V\%C3\%A1rios_2010.pdf>. Acesso em: 12 nov. 2015.

GRAY, D. E. Pesquisa no mundo real. Porto Alegre: Penso, 2012.

HILÁRIO, T.; REIS, P. R. Potencialidades e limitações de sessões de discussão de controvérsias sociocientíficas como contributos para a literacia científica. Revista de

Estudos Universitários, Sorocaba, v. 35, n. 2, p.167-183, 2009. Disponível em: <http:// repositorio.ipsantarem.pt/bitstream/10400.15/31/1/568-1310-1-PB.pdf>. Acesso em: 12 nov. 2015.

HODSON, D. Looking to the future: building a curriculum for social activism. Rotterdam: Sense Publishers, 2011. Disponível em: <https://www.sensepublishers.com/media/621looking-to-the-future.pdf>. Acesso em: 12 nov. 2015.

. Time for action: science education for an alternative future. International Journal of Science Education, London, v. 25, n. 6, p. 645-670, 2003.

LEVINSON, R. Towards a theoretical framework for teaching controversial socioscientific issues. International Journal of Science Education, Abingdon, v. 28, n. 10, p.1201-1224, 2006.

LIMA, J. R.; CAPITÃO, Z. E-learning e e-conteúdos: aplicações das teorias tradicionais e modernas de ensino e aprendizagem à organização e estruturação de recursos. Lisboa: Centro Atlântico, 2003. Disponível em: <http://www.centroatl.pt/titulos/si/imagens/ebook-ca-e-learning-excerto.pdf>. Acesso em: 12 nov. 2015.

LINHARES, E. F. A discussão como metodologia de educação em ciências no ensino superior. 488 f. Tese. (Doutoramento em Educação) - Instituto de Educação, Universidade de Lisboa, Lisboa, 2013. Disponível em: < http://repositorio.ul.pt/handle/10451/8691>. Acesso em: 12 nov. 2015. 
As tecnologias da informação e da comunicação ...

LINHARES, E.; REIS, P. A discussão de controvérsias sócio-científicas a partir de documentários em vídeo. In: MEMBIELA, P.; CASADO, N.; CEBREIROS, M. I. (Ed.). Retos y perspectivas em la enseñanza de las ciencias. Roma: Educación Editora, 2012. p. $115-120$.

MARQUES, A. R. L. As potencialidades de uma abordagem interdisciplinar entre as ciências naturais e a tecnologias da informação e da comunicação no desenvolvimento de um projeto de ativismo ambiental. 247 f. Dissertação (Mestrado em Ensino de Biologia e Geologia) - Instituto de Educação, Universidade de Lisboa, Lisboa, 2013. Disponível em: <http://repositorio.ul.pt/handle/10451/10206>. Acesso em: 12 nov. 2015.

MONTEIRO, M. E. P. F. O ensino da biologia e geologia com recurso às tecnologias da informação e comunicação: Implicações para a aprendizagem. 408 f. Tese (Doutoramento em Educação) - Instituto de Educação, Universidade de Lisboa, Lisboa, 2013. Disponível em: <http://repositorio.ul.pt/handle/10451/10598>. Acesso em: 12 nov. 2015.

MORAN, J. M. et al. Novas tecnologias e mediação pedagógica. 6. ed. Campinas: Papirus, 2000.

OULTON, C.; DILLON, J.; GRACE, M. Reconceptualising the teaching of controversial issues. International Journal of Science Education, Abingdon, v. 26, n. 4, p. 411-423, 2004.

PAPERT, S. Change and resistance to change in education: taking a deeper look at why school hasn't changed. In: NOVO conhecimento, nova aprendizagem. Lisboa: Fundação Calouste Gulbenkian, 2001. p. 61-70.

PEREIRA, B. T. O uso das tecnologias da informação e comunicação na prática pedagógica da escola. Curitiba: Secretaria da Educação, 2010. Disponível em: <http:// www.diaadiaeducacao.pr.gov.br/portals/pde/arquivos/1381-8.pdf>. Acesso em: 20 out. 2013.

POZO, J. I. Aquisição de conhecimento. Porto Alegre: Artmed, 2004.

PRENSKY, M. Digital natives, digital immigrants: part 1. On the Horizon, Bingley, v. 9, n. 5, p. 1-6, 2001. Disponível em: <http://www.marcprensky.com/writing/Prensky\%20-\%20 Digital $\% 20$ Natives, $\% 20$ Digital $\% 20$ Immigrants \%20-\%20Part1.pdf > . Acesso em: 12 nov. 2015.

REIS, P. Ciência e controvérsia. Revista de Estudos Universitários, Sorocaba, v. 35, n. 2, p. 9-15, 2009. Disponível em: < http://repositorio.ul.pt/handle/10451/4615>. Acesso em: 12 nov. 2015.

. Controvérsias sócio-científicas: discutir ou não discutir?: percursos de aprendizagem na disciplina de ciências da Terra e da vida. Tese (Doutoramento em Educação) - Departamento de Educação, Faculdade de Ciências, Universidade de Lisboa, Lisboa, 2004. Disponível em: <http://repositorio.ul.pt/handle/10451/3109>. Acesso em: 12 nov. 2015. 
REIS, P. Da discussão à ação sociopolítica sobre controvérsias sócio-científicas: uma questão de cidadania. Ensino de Ciências e Tecnologia em Revista, Santo Ângelo, v. 3, n. 1, p. 1-10, 2013.

- A promoção do pensamento através da discussão dos novos avanços na área da biotecnologia e da genética. Dissertação (Mestrado em Educação) - Departamento de Educação, Faculdade de Ciências, Universidade de Lisboa, Lisboa, 1997.

. Promoting students' collective socio-scientific activism: teachers' perspectives. In: BENCZE, L.; ALSOP, S. (Ed.). Activist science and technology education. Dordrecht: Springer, 2014. p. 547-574. (Cultural Studies of Science Education, v. 9).

Os temas controversos na educação ambiental. Pesquisa em Educação Ambiental, Ribeirão Preto, v. 2, n. 1, p. 125-140, 2007.

REIS, P.; GALVÃO, C. Socio-scientific controversies and students' conceptions about scientists. International Journal of Science Education, Abingdon, v. 26, n. 13, p. 1621-1633, 2004.

SADLER, T.; ZEIDLER, D. The morality of socioscientific issues: construal and resolution of genetic engineering dilemmas. Science Education, Dordrecht, v. 88, n. 1, p. 4-27, 2004.

UNIVERSIDADE DE LISBOA. Repositório UL. Disponível em: < http:// repositorio. ul.pt/>. Acesso em: 12 nov. 2015.

VALÉRIO, A. M. C. P. Podcasting e vodcasting na disciplina de química do $9^{\circ}$ ano de escolaridade. 94 f. Dissertação (Mestrado em Didática das Ciências) - Instituto de Educação, Universidade de Lisboa, Lisboa, 2012. Disponível em: <http:/ / repositorio.ul.pt/ handle/10451/8190>. Acesso em: 12 nov. 2015.

VERAS, M. (Org). Inovação e métodos de ensino para nativos digitais. São Paulo: Atlas, 2011.

VOSLOO, S. Unesco policy guidelines for mobile learning: version 2.1: draft. [S.1.]: Unesco, 2012. Disponível em: <http:/ /www.unesco.org/new/fileadmin/MULTIMEDIA/ HQ/ED/pdf/UNESCO_Policy_Guidelines_on_Mobile_Learning_DRAFT_v2_1_ FINAL_2_.pdf>. Acesso em: 20 abr. 2014.

ZEICHNER, K. A formação reflexiva de professores: ideias e práticas. Lisboa: Educa, 1993.

Artigo recebido em 30/07/2014. Aceito em 20/07/2015.

Endereço para contato:

Rua Estilac Leal, 828, Bairro Pascotini, CEP 98803-190, Santo

Ângelo, RS, Brasil. 